\title{
Observations on sporulation of Eimeria bovis (Apicomplexa: Eimeriidae) from the European bison Bison bonasus: effect of temperature and potassium dichromate solution
}

\author{
Anna M. Pyziel and Aleksander W. Demiaszkiewicz
}

W. Stefański Institute of Parasitology, Polish Academy of Sciences, Warsaw, Poland

\begin{abstract}
The present study was designed to determine the influence of temperature and the addition of potassium dichromate solution $\left(\mathrm{K}_{2} \mathrm{Cr}_{2} \mathrm{O}_{7}\right)$ on the efficiency of sporulation of Eimeria bovis (Zublin, 1908), a coccidian species most commonly diagnosed in European bison Bison bonasus (Linnaeus). Sporulation under conventional conditions ( $2.5 \%$ dichromate solution, $\left.23^{\circ} \mathrm{C}\right)$ was completed on the fourth day of incubation (control), whereas the oocyst development took two days more at the temperature of $18^{\circ} \mathrm{C}$, and two days less at $28^{\circ} \mathrm{C}$. Additionally, experimental sporulation of E. bovis at the temperature of $23^{\circ} \mathrm{C}$ in the environment of sterilised tap water (without any preservation) took 9 days more compared to control. Finally, oocyst development took 16 weeks when the faces were stored in the refrigerator $\left(3-5^{\circ} \mathrm{C}\right)$ without any special additives. Overall, our results indicate that $\mathrm{K}_{2} \mathrm{Cr}_{2} \mathrm{O}_{7}$, besides the temperature, plays a crucial role in the process of sporulation of oocysts under laboratory conditions, as the longest delay in sporogony was observed when the faeces were stored without any other additives in the temperature of the refrigerator.
\end{abstract}

Keywords: coccidia, experimental development of oocysts, wisent, Bialowieza Primeval Forest

Coccidia from the genus Eimeria Schneider, 1875 (Apicomplexa: Eimeriidae) are widespread protozoan parasites of economic importance of livestock production, due to increasing mortality rates of calves, reduction in food intake and decrease of body mass as well as body size of infected animals (Fitzgerald 1980). Life cycles of species of Eimeria are simple and begin when infective (sporulated) oocysts are ingested by a susceptible host. Asexual and sexual stages occur within the intestinal epithelial cells of a host, but the symptoms of coccidiosis and pathological changes are associated with the sexual stages of development (Hammond et al. 1946). The third stage of eimerian development, sporogony, takes place outside the host.

Time required for sporulation is one of diagnostic criteria for identification of coccidia, but no data are available on experiments under optimised conditions, as the most of experiments were carried out at room temperature (Christensen 1941, Bhatia et al. 1968, Ryff and Bergstrom 1975, Golemansky 2003). Moreover, the majority of previous studies on sporulation of eimerians of bovids had been done before guidelines of Duszynski and Wilber (1997) were available.

Eimeria bovis (Zublin, 1908) is regarded as the most pathogenic species of coccidia in cattle, responsible for outbreaks of clinical coccidiosis of calves (Chibunda et al. 1997, Pandit 2009). According to our previous study, E. bovis was the most prevalent species of eimerians (prevalence $30 \%$; 50-6 150 oocysts per gram [OPG]) diagnosed in the European bison, but no symptoms of coccidiosis were observed (Pyziel et al. 2014).

The objective of the present study was to determine the sporulation time of $E$. bovis, the most prevalent species of Eimeria, in the European bison (Bison bonasus Linnaeus), under conventional and experimental conditions.

The present studies were conducted between 2007 and 2011, simultaneously with a study on determining the composition of eimerian species infecting European bison in Poland. Fresh faecal samples with the highest number of oocysts of E. bovis per gram (3 150-6000 OPG) were placed in Petri dishes, which were being closed afterwards (to prevent dehydration of faecal material) and prepared for sporulation in different conditions.

Some of them were used as a control for sporulation potential of the oocysts; they were incubated conventionally $\left(23^{\circ} \mathrm{C}, 5\right.$ volumes of $2.5 \% \mathrm{~K}_{2} \mathrm{Cr}_{2} \mathrm{O}_{7}: 1$ volume of faeces) for 4 days, following the guidlines of Duszynski and Wilber (1997), with the use of Inkubator I - 65W 71L (WAMEM Wytwórnia Aparatury Medycznej SSP, Warsaw, Poland). Two experiments were performed in modified thermal conditions without changing any other factor $\left(18^{\circ} \mathrm{C}\right.$ for 8 days and $28^{\circ} \mathrm{C}$ for 3 days, respectively). 

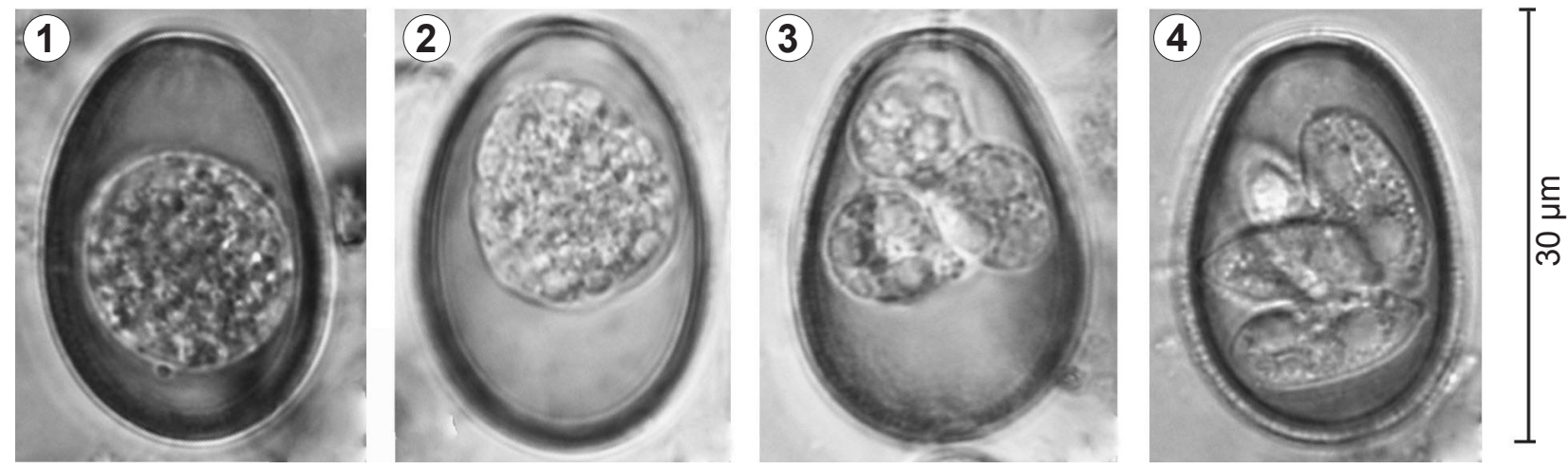

Fig. 1. Oocyst before incubation at $23{ }^{\circ} \mathrm{C}$, in $2.5 \% \mathrm{~K}_{2} \mathrm{Cr}_{2} \mathrm{O}_{7}$. Fig. 2. Irregular sporont composed of enlarged granules; 24 hours of incubation. Fig. 3. Young, not fully formed sporocysts containing discernible sporozoites; 48 hours of incubation. Fig. 4. Fully sporulated oocyst; 72-96 hours of incubation.

One study was carried out in the environment of sterile tap water (to prevent fungal and bacterial growth), instead of $2.5 \% \mathrm{~K}_{2} \mathrm{Cr}_{2} \mathrm{O}_{7}$, at the conventional temperature of $23^{\circ} \mathrm{C}$ for 25 days. In the last experiment, pure faeces were stored in refrigerator $\left(3-5^{\circ} \mathrm{C}\right)$ for 112 days without any special additives. The degree of sporulation was observed daily by microscopical examination of samples obtained by direct flotation as described in Pyziel and Demiaszkiewicz (2013). Morphological features of sporulating oocysts were studied at $\times 1000$ magnification using light microscopy (Olympus BX50) and Cell D software package.

\section{Sporulation under conventional conditions - control}

Some features of initial zygote development were observed after the first day of incubation (Fig. 1). Sporoplasm within the oocyst became spongy, irregular, consisted of enlarged granules (Fig. 2). Neither pyramidal stages of development nor stage containing four undifferentiated sporoblasts precluding formation of sporocysts were observed during the study (Jirků et al. 2009). During the second day of incubation young, not fully formed sporocysts containing discernible sporozoites were present (Fig. 3). Thus, in the third day of the experiment, oocysts containing four oval sporocysts carrying Stieda body, containing two sporozoites were noted, but the internal structure of sporocysts could not be observed. At the fourth day of incubation the sporulation was completed with the typical structure of sporocysts and sporozoites inside the oocyst (Fig. 4). The percentage of sporulated oocysts was $47 \%$.

\section{Sporulation under experimental conditions}

Phases of development of zygote within the oocyst were in accordance with the features mentioned above, but the process of sporulation was completed within different time depending on temperature used and addition of $2.5 \%$ $\mathrm{K}_{2} \mathrm{Cr}_{2} \mathrm{O}_{7}$.

\section{Sporulation at $18^{\circ} \mathrm{C}$}

The first sporulated oocysts were observed at the sixth day of incubation, but the percentage of sporulated oocysts was low, reaching $32 \%$. The highest percentage of sporu- lated oocysts (80\%) was observed at the eight day of incubation.

\section{Sporulation at $28^{\circ} \mathrm{C}$}

Sporulation was completed at the second day of incubation, with the percentage of sporulated oocysts reaching $37 \%$, whereas the highest sporulation rate, reaching $90 \%$ was seen at the third day of experiment.

\section{Sporulation in a sterile tap water at $23^{\circ} \mathrm{C}$}

The first completly sporulated oocysts were seen as late as the 12th day of incubation when the percentage of sporulated oocysts was $18 \%$. At the 25 th day of the experiment $100 \%$ oocysts were sporulated.

\section{Sporulation under conditions of the refrigerator at $3-5^{\circ} \mathrm{C}$}

Sporulated oocysts were observed at the 16th week (112th day) of experiment and the percentage of sporulated oocysts reached $72 \%$.

The results of this study showed that process of sporulation was the quickest and the most efficient at the temperature of $28^{\circ} \mathrm{C}$ in the environment of $2.5 \% \mathrm{~K}_{2} \mathrm{Cr}_{2} \mathrm{O}_{7}$. Further decline of temperature of incubation by $5^{\circ} \mathrm{C}$ (from $28^{\circ} \mathrm{C}$ to $23^{\circ} \mathrm{C}$ and $18^{\circ} \mathrm{C}$, respectively) resulted in 2 days of delay in sporulation. These results are consistent with those of Edgar (1954) who reported the most rapid sporulation of Eimeria tenella (Railliet et Lucet, 1891) oocysts at the temperature of $29^{\circ} \mathrm{C}$. Moreover, the present study has revealed that sporulation of oocysts incubated at $23^{\circ} \mathrm{C}$ stored without the addition of potassium dichromate took 9 days more compared to the control. This finding is in agreement with the results of Lotze and Leek (1961) who showed that time required for sporulation of oocysts was longer when no antiputrefactive agents, such as dichromate, were used.

This study confirms that potassium dichromate solution, besides temperature, plays a crucial role in process of sporulation under laboratory conditions, as the longest delay in sporogony was observed when the faeces were stored without any other additives in the temperature of the refrigerator, which resulted in 28 -fold slower sporulation 
in comparison with the control. We suppose that the conditions of the experiment mentioned above resemble natural conditions that occur in the Bialowieza Forest, where the mean annual air temperature is $7^{\circ} \mathrm{C}$ and the average temperature of the warmest month (July) does not exceed $19^{\circ} \mathrm{C}$ (Krasińska and Krasiński 2007). Moreover, it cannot be excluded that some oocysts are able to survive winter and become infective at the beginning of grazing season, which would explain the April peak in prevalence and OPG values reported in our previous study on the annual cycle of shedding coccidian oocysts by bison (Pyziel et al. 2011).

Marquardt et al. (1960) observed that the lowest temperature for surviving of Eimeria zuernii (Rivolta, 1878) oocysts from cattle (Bos taurus Linnaeus) was $-7^{\circ} \mathrm{C}$, whereas the mean daily temperature in Bialowieza in the coldest month (January) is $-4.8^{\circ} \mathrm{C}$ (Krasińska and Krasiński 2007). The present study showed that sporulation time of oocysts of E. bovis was 3-4 days under the conditions recommended by Duszynski and Wilber (1997). This result matches with that observed by Bhatia et al. (1968) on oocysts of E. bovis from Indian buffalo (Bubalus bubalis Linnaeus). However, Golemansky (2003) found that sporulation of E. bovis from European bison was completed within 2 days in a room temperature. Additionally, no data are avaiable for sporulation time of $E$. bovis from American bison (Bison bison Linnaeus) (Penzhorn et al. 1994).

Acknowledgments. The data presented in this study form part of a PhD study by AMP; her PhD studies were supported by the Ministry of Science and Higher Education of Poland (grant No. N N308 234738).

\section{REFERENCES}

Bhatia B.B, Pande B.P., Chauhan P.P.S., Arora G.S. 1968 A study on the sporulated oocysts of twelve eimerian species in Indian buffalo (Bubalus bubalis). Acta Vet. Acad. Sci. Hung. 18: 115-133.

Chibunda R.T., Muhairwa A.P., Kambarage D.M., Mtambo M.M.A., Kusiluka L.J.M., Kazwala R.R. 1997: Eimeriosis in dairy cattle farms in Morogoro municipality of Tanzania. Prev. Vet. Med. 31: 191-197.

Christensen J.F. 1941: The oocysts of coccidian from domestic cattle in Alabama (U.S.A.), with descriptions of two new species. J. Parasitol. 27: 203-220.

Duszynski D.W., Wilber P.G. 1997: A guideline for the preparation of species descriptions in the Eimeriidae. J. Parasitol. 83: 333-336.

EDGAR S.A. 1954: Effect of temperature on the sporulation of oocysts of the protozoan, Eimeria tenella. Trans. Amer. Micr. Soc. 73: $237-242$.

FitzGerald P.R. 1980: The economic impact of coccidiosis in domestic animals. Adv. Vet. Sci. Comp. Med. 24: 121-143.

Golemansky V. 2003: Intestinal coccidians of wild mammals from Bulgaria. Acta Zool. Bulgar. 55: 49-54.

Hammond D.M., Bowman G.W., Davis L.R., Simms B.T. 1946: The endogenous phase of the life cycle of Eimeria bovis. J. Parasitol. 32: 409-427.

JirkŮ M., JiRkŮ M., Oborník M., Lukeš J., ModrÝ D. 2009: A model for taxonomic work on homoxenous coccidia: redescription, host specificity, and molecular phylogeny of Eimeria ranae
Dobell, 1909, with a review of anuran-host Eimeria (Apicomplexa: Eimeriorina). J. Eukaryot. Microbiol. 56: 39-51.

Lotze J.C., Leek R.G. 1961: A practical method for culturing coccidial oocysts in tap water. J. Parasitol. 47: 588-590.

Marquardt W.C., Senger C.M., Seghetti L. 1960: The effect of physical and chemical agents on the oocyst of Eimeria zuernii (Protoza, Coccidia). J. Protozool. 7: 186-189.

Krasińska M., Krasiński Z. (Eds.) 2007: The European Bison. A Nature Monograph. Mammal Research Institute, Polish Academy of Sciences, Białowieża, 79 pp.

Pandit A.B. 2009: Prevalence of coccidiosis in cattle in Kashmir Valley. VetScan 4: 16-20.

Penzhorn B.L., Knapp S.E., Speer C.A. 1994: Enteric coccidia in free-ranging American bison (Bison bison) in Montana. J. Wildlife Dis. 30: 267-269.

Pyziel A.M., Demiaszkiewicz A.W. 2013: Coccidia (Apicomplexa: Eimeriidae) of elk (Alces alces) in Poland. Parasitol. Res. 112: 2083-2085.

Pyziel A.M., Jóźwikowski M., Demiaszkiewicz A.W. 2014: Coccidia (Apicomplexa: Eimeriidae) of the lowland European bison Bison bonasus (L.). Vet. Parasitol. 202: 138-144.

Pyziel A.M., Kowalczy K R., Demiaszkiewicz A.W. 2011: The annual cycle of shedding Eimeria oocysts by European bison (Bison bonasus) in the Bialowieza Primeval Forest, Poland. J. Parasitol. 97: 737-739.

RyfF K.L., Bergstrom R.C. 1975: Bovine coccidia in American bison. J. Wildlife Dis. 11: 412-414. 